\title{
Design and Simulation Analysis of Three-phase Transformer less Grid-connected PV Inverters
}

\author{
Jayanna Kanchikere ${ }^{1}$, A. K. Ghosh ${ }^{2}$, Kalyankumar ${ }^{3}$ \\ ${ }^{1}$ Department of EEE, St.Peter's Engineering College, Hyderabad, India \\ ${ }^{2,3}$ Vinayaka Missions Sikkim University, Sikkim, India
}

\begin{tabular}{l}
\hline \hline Article Info \\
\hline Article history: \\
Received Jul 16, 2018 \\
Revised Aug 5, 2018 \\
Accepted Aug 23, 2018 \\
\hline
\end{tabular}

\section{Keywords:}

Common-Mode Voltage

(CMV)

Framework

Photovoltaic (PV)

Spillage present

Transformer less

\begin{abstract}
Three-stage transformer less inverter is broadly utilized as a part of low power photovoltaic (PV) framework associated frameworks because of its little size, high proficiency and ease. At the point when no transformer is utilized as a part of a framework associated PV framework, a galvanic association between the lattice and PV exhibit exists. In these conditions, perilous spillage streams (basic mode ebbs and flows) can show up through the stray capacitance between the PV cluster and the ground. The previous, keeping in mind the end goal to make a galvanic separation between the info and the yield incorporate a transformer (obligatory in a few nations) that restrains the entire framework exhibitions as far as effectiveness, weight, size and cost. Actually, transformer less inverters don't present any separation and are described by minimal size, bring down cost and higher effectiveness (over $2 \%$ higher). In any case, the absence of transformers prompts spillage streams that can be hurtful to the human body, and in addition for the entire transformation framework uprightness. With a specific end goal to keep away from the spillage streams, different Transformer less inverters have been proposed utilizing diverse topologies to create consistent regular mode voltage. In this paper, different as of late proposed transformer less PV inverters are researched. Their exhibitions are thought about and broke down.
\end{abstract}

Copyright $\odot 2018$ Institute of Advanced Engineering and Science. All rights reserved.

\section{Corresponding Author:}

Jayanna Kanchikere,

Department of EEE,

St. Peter's Engineering College,

Hyderabad, India.

Email: jayannak69@gmail.com

\section{INTRODUCTION}

Today, the vitality request is expanding because of the quick increment of the human populace and quickly developing ventures. Consequently, sustainable power source assumes a vital part to supplant conventional regular assets, for example, fuel and coal. Photovoltaic (PV) vitality has as of late turned into a typical enthusiasm of research since it is free, green, and limitless [1], [2]. Moreover, PV frameworks are currently more moderate because of government motivators, progression of intensity hardware and semiconductor innovation and cost lessening in PV modules [3], [4].

By and large, there are two sorts of matrix associated PV frameworks, I. e., those with transformer and without transformer. The transformer utilized can be high recurrence (HF) transformer on the dc side or low recurrence transformer on the air conditioner side [5]. Other than venturing up the voltage, it assumes an imperative part in security reason by giving galvanic detachment, and in this way taking out spillage current and evading dc current infusion into the lattice. By and by, the transformers are cumbersome, substantial, and costly. Despite the fact that critical size and weight decrease can be accomplished with HF transformer, the utilization of transformer still lessens the effectiveness of the whole PV framework [6]. Consequently, 
transformer less PV frameworks is acquainted with beaten these issues. They are littler, lighter, bringing down in cost and profoundly proficient [7].

High recurrence basic mode $(\mathrm{CM})$ voltages must be dodged for a transformer less PV framework associated inverter since it will prompt a huge charge/release current somewhat moving through the inverter to the ground. This CM ground current will cause an expansion in the present sounds, higher misfortunes, security issues, and electromagnetic impedance (EMI) issues For a network associated PV framework, vitality yield and payback time are incredibly subject to the inverter's unwavering quality and proficiency, which are viewed as two of the most noteworthy attributes for PV inverters. Keeping in mind the end goal to limit the ground spillage current and enhance the productivity of the converter framework, transformer less PV inverters using unipolar PWM control have been displayed [8-10]. The weighted California Energy Commission (CEC) or European Union (EU) efficiencies of most industrially accessible and writing detailed single-stage PV transformer less inverters are in the scope of 96-98\% The revealed framework pinnacle and CEC efficiencies with a $8-\mathrm{kW}$ converter framework from the item datasheet is $98.3 \%$ and $98 \%$, individually, with $345-\mathrm{V}$ dc input voltage and a $16-\mathrm{kHz}$ exchanging recurrence.

In any case, this topology has high conduction misfortunes because of the way that the current must lead through three switches in arrangement amid the dynamic stage. Another drawback of the H5 is that the line-recurrence switches S1 and S2 can't use MOSFET gadgets on account of the MOSFET body diode's moderate turn around recuperation. Supplanting the switch S5 of the H5 inverter with two split switches S5 and S6 into two stage legs and including two freewheeling diodes D5 and D6 for freewheeling current streams, the H6 topology was proposed in [11], [12]. The H6 inverter can be executed utilizing MOSFETs for the line recurrence exchanging gadgets, taking out the utilization of less proficient IGBTs. The detailed pinnacle proficiency and EU effectiveness of a $300 \mathrm{~W}$ model circuit were $98.3 \%$ and $98.1 \%$, individually, with $180 \mathrm{~V}$ dc input voltage and $30 \mathrm{kHz}$ exchanging recurrence [13].

Keeping in mind the end goal to address these two key issues, another inverter topology is proposed for three-stage transformer less PV framework associated frameworks in this paper. The proposed transformer less PV inverter highlights: 1) high unwavering quality in light of the fact that there are no shootthrough issues, 2) low yield air conditioning current bending because of no dead-time necessities at each PWM exchanging recompense moment and also at framework zero-intersection moments, 3) limited CM spillage current on the grounds that there are two extra air conditioning side switches that decouple the PV cluster from the network amid the freewheeling stages, and 4) all the dynamic switches of the proposed converter can dependably utilize super intersection MOSFETs since it never has the opportunity to initiate MOSFET body diode turn around recuperation. Because of the low conduction and exchanging misfortunes of the super intersection MOSFETs, the proposed converter can be intended to work at higher exchanging frequencies while keeping up high framework proficiency. Higher exchanging frequencies diminish the air conditioner current swell and the span of aloof segments [14].

\section{BASIC MODE BEHAVIOR AND LEAKAGE CURRENT REDUCTION METHODS}

At the point when the transformer is expelled from the inverter, a resounding circuit is framed as appeared in Figure 1(a). This full circuit incorporates stray capacitance (CPV), the channel inductors (L1 and L2), and spillage current (IL). Here, the power converter is spoken to by a square with four terminals to permit a general portrayal of different converter topologies. On the dc side, $\mathrm{P}$ and $\mathrm{N}$ are associated with the positive and negative rail of the dc-interface, separately; while on the air conditioner side, terminals An and $\mathrm{B}$ are associated with the single-stage network by means of channel inductors. From the view purpose of the framework, the power converter square appeared in Figure 1(a) can be considered as voltage sources, creating voltage VAN and VBN.

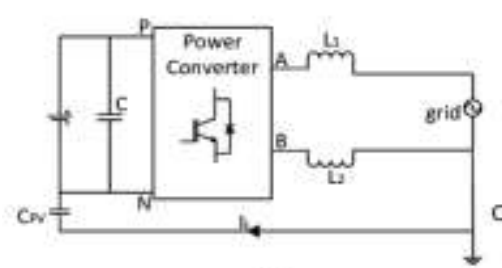

(a)

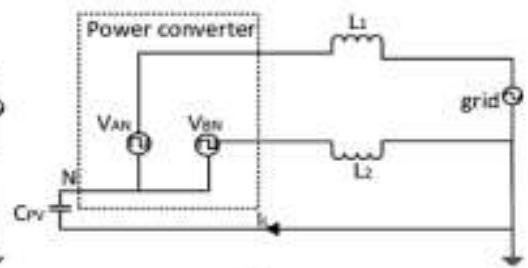

(b)

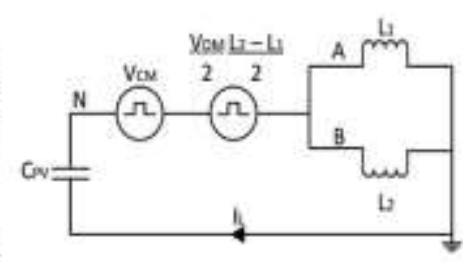

(c)

Figure 1. Common-mode model for single-phase grid-connected inverter (a) Full model (b) Simplified model (c) Simplified common-mode model 
Thus, paying little respect to the transformation structure, this power converter square can be streamlined into the proportional circuit which comprises of VAN and VBN as appeared in Figure 2(b). The spillage current is in this manner an element of VAN, VBN, matrix voltage, channel inductance, and stray capacitance. The CMVVCM and differential-mode voltage VDM can be characterized as

$$
\begin{aligned}
& \boldsymbol{V}_{C M}=\frac{\boldsymbol{V}_{A N}+\boldsymbol{V}_{B N}}{2} \\
& \boldsymbol{V}_{D M}=\boldsymbol{V}_{A N}-\boldsymbol{V}_{B N}
\end{aligned}
$$

Rearranging (1) and (2), the output voltages can be expressed in terms of $\mathrm{V}_{\mathrm{CM}}$ and $\mathrm{V}_{\mathrm{DM}}$ as

$$
\begin{aligned}
& \boldsymbol{V}_{A N}=\boldsymbol{V}_{C M}+\frac{\boldsymbol{V}_{D M}}{2} \\
& \boldsymbol{V}_{B N}=\boldsymbol{V}_{C M}-\frac{\boldsymbol{V}_{D M}}{2} \\
& \boldsymbol{V}_{E C M}=\boldsymbol{V}_{C M}+\frac{\boldsymbol{V}_{D M}}{2} \frac{\boldsymbol{L} 2-\boldsymbol{L} 1}{\boldsymbol{L} 1+\boldsymbol{L} 2}
\end{aligned}
$$

Since identical filter inductors (L1 =L2) are use dint is Paper, the VECM is equal to VCM

$$
\boldsymbol{V}_{E C M}=\boldsymbol{V}_{C M}=\frac{\boldsymbol{V}_{A N}+\boldsymbol{V}_{B N}}{2}
$$

From the model, it can be presumed that the spillage current is particularly needy of the CMV. Accordingly, converter structure and the balance strategy must be intended to create consistent CMV so as to dispense with the spillage current. It merits featuring that the model in Figure 1(c) has been generally utilized for portraying the basic mode conduct of the customary full-connect (H4) topology. Nonetheless, because of the all inclusive statement of the model, clearly the model is substantial for different topologies examined here, aside from H4. In actuality, a similar model has been utilized to investigate the regular mode conduct of different transformers less converter topologies. Be that as it may, since various topology has diverse VAN and VBN, the articulations for VCM and VDM will contrast from each other, common-mode behavior. Hence, to evaluate the common mode. Conduct of a specific topology, VAN and VBN under various changing condition should be assessed, as will be demonstrated later.

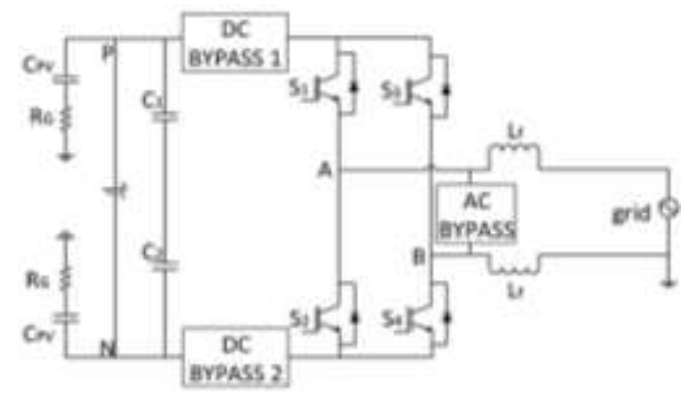

Figure 2. Universal transformer less topologies

\subsection{Galvanic isolation}

In changed less PV inverters, the galvanic association between the PV and the matrix enables spillage current to stream. Consequently, in topologies, for example, H5 and HERIC, galvanic segregation is given to diminish the spillage current. The galvanic seclusion can essentially be ordered into dc-decoupling 
and air conditioning decoupling strategies. For dc-decoupling strategy, dc-sidestep switches are included the dc side of the inverter to disengage the PV clusters from the matrix amid the freewheeling time frame. In any case, the dc-sidestep branch, which comprises of switches or diodes, is incorporated into the conduction way as appeared in Figure 3. For H6, yield current moves through two switches and the two dc-sidestep branches amid the conduction time frame. Subsequently, the conduction misfortunes increment because of the expanded number of semiconductors in the conduction way. Then again, sidestep branch can likewise be given on the air conditioner side of the inverter (i.e., air conditioning decoupling strategy, for example, seen in HERIC. This air conditioner sidestep branch works as a freewheeling way which is totally disconnected from the conduction way, as appeared in Figure 2. Thus, the yield current moves through just two switches amid the conduction time frame. Accordingly, topologies utilizing air conditioning decoupling methods are observed to be higher in effectiveness when contrasted with dc-decoupling topologies. One misfortune of galvanic seclusion is that there is no chance to get of controlling the CMV by PWM amid the freewheeling time frame. Figure 3 indicates activity methods of galvanic detachment which.

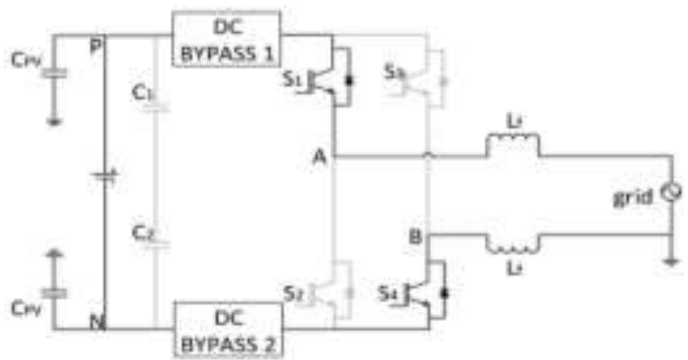

(a)

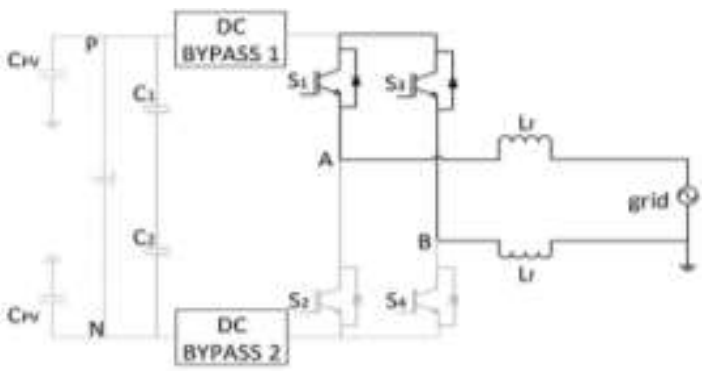

(b)

Figure 3. Operation modes of Dc-decoupling topology (a) Conduction mode and (b) Freewheeling mode

Utilizes dc-decoupling strategy. As appeared in Figure 3 (an), amid the conduction time frame, S1 and S4 lead to produce the coveted yield voltage. In the meantime, VA is straightforwardly associated with VDC and VB is associated with the negative terminal $(\mathrm{N})$ of the dc-connect. Consequently, the CMV progresses toward becoming.

$$
\boldsymbol{V}_{C M}=\frac{\boldsymbol{V}_{A N}+\boldsymbol{V}_{B N}}{2}=\frac{1}{2}\left(\boldsymbol{V}_{D C}+0\right)=\frac{\boldsymbol{V}_{D C}}{2}
$$

All things considered, amid the freewheeling time frame, the dc-sidestep switches separate the dcinterface from the matrix. Along these lines, point An and point B are detached from the dc-connection, and VA and VB are coasting as for the dc-interface as appeared in Figure 3(b). The CMV amid this timeframe isn't dictated by the exchanging state, however rather, is swaying with plentifulness relying upon the parasitic parameters and the switches' intersection capacitances of the comparing topology. Thus, spillage current can in any case stream amid freewheeling period. The same is the situation for converters utilizing air conditioning decoupling strategy.

\subsection{CMV clamping}

As specified before, CMV is one of the fundamental drivers for spillage momentum. H5 and HERIC concentrate just on giving galvanic segregation while dismissing the impact of the CMV. Not at all like ordinary topologies, the CMV in these topologies can't be controlled by means of PWM, because of the utilization of galvanic confinement as clarified beforehand. With a specific end goal to create steady CMV bracing branch is presented in OH5. Figure 4 shows proposed hbzvr-d topology (a) Converter structure, (b) Switching waveforms. 


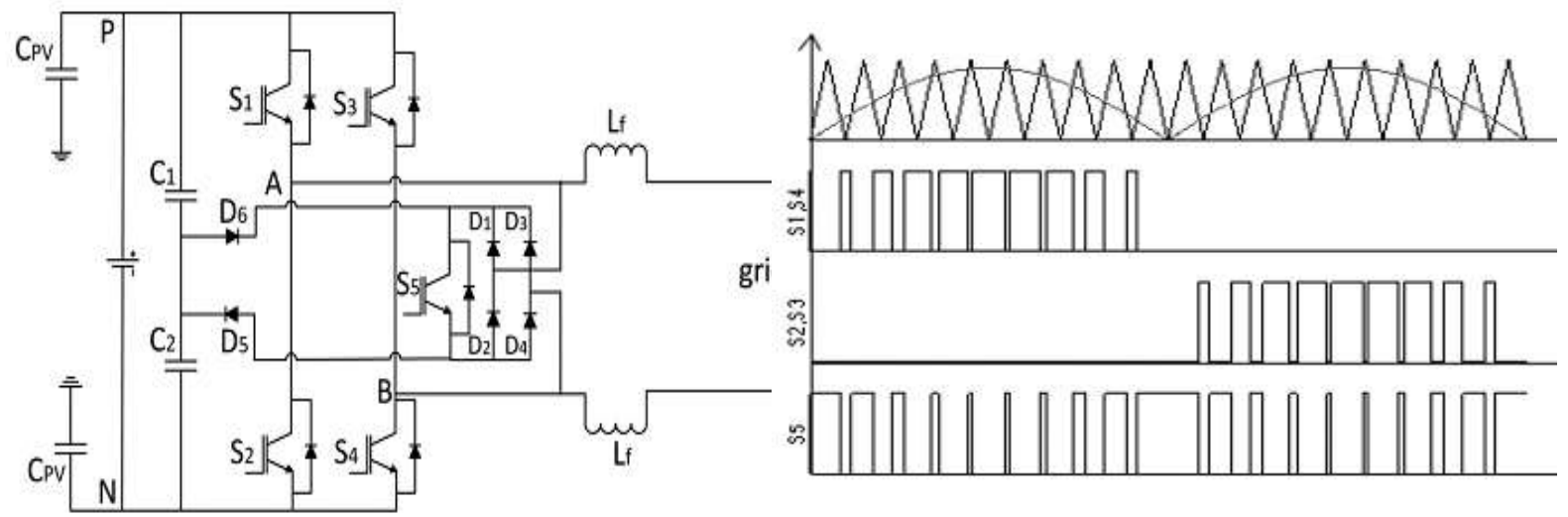

(a)

(b)

Figure 4. Proposed HBZVR-D topology (a) Converter structure (b) Switching waveforms

For the most part, the clasping branch comprises of diode or switches and a capacitor divider which guarantees the freewheeling way is clipped to the half of the info voltage. With the consolidated impact of galvanic disconnection and CMV clipping, spillage current is totally overlaid. All things considered, both H6 and OH5 utilizes dc-decoupling technique, which experiences bring down proficiency. HBZVR likewise utilizes CMV clasping strategy however it is discovered that the clipping branch does not work ideally. It is appeared in both the recreation and test comes about that the CMV and the spillage current in HBZVR are as high as those in the topologies which utilize just galvanic separation.

\section{ACTIVITY PRINCIPLES OF PROPOSED TOPOLOGY}

\subsection{Structure of proposed HBZVR-D}

In light of the examination over, a straightforward changed HBZVR-D is proposed to consolidate the advantages of the low-misfortune air conditioning decoupling strategy and the entire spillage current disposal of the CMV cinching technique. HBZVR-D is changed by including a quick recuperation diode, D6, to the current HBZVR as appeared in Figure 4(a). The voltage divider is comprised of C1and C2.S1-S4 are for full-connect inverter. The counter parallel diodes, D1-D4, and in addition S5 give a freewheeling way to the current to stream amid the freewheeling time frame. Diodes D5 and D6 form the bracing branches of the freewheeling way.

\subsection{Activity modes and analysis}

In this segment, the activity modes and the CMV of the proposed topology is examined. Figure 4(b) delineates the exchanging (c) Mode 3-conduction mode and (d) Mode 4-freewheeling mode amid negative half cycle Patterns of the proposed HBZVR-D. Figure 5 Operation Modes of Proposed HBZVR-D Topology. (a) Mode 1-Conduction Mode and (b) Mode 2-Freewheeling Mode during Positive Half Cycle.

SwitchesS1-S4 commutate at changing recurrence to produce unipolar yield voltage. S5 commutates reciprocally to S1-S4 to make freewheeling way. All the four activity modes are appeared in Figure 6 . To create unipolar yield voltage. In mode 1, S1 and S4 are ON while S2, S3 and S5 are OFF. Current increments and streams through $\mathrm{S} 1$ and $\mathrm{S} 4 . \mathrm{VAB}=+\mathrm{VDC}$. The CMV moves toward becoming. 


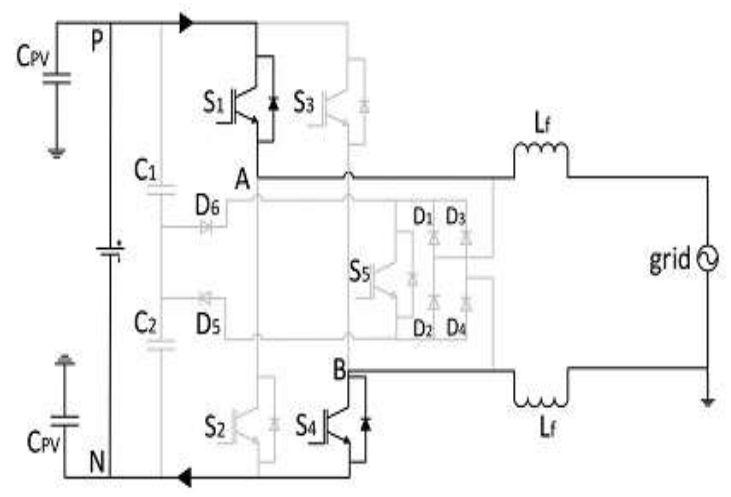

(a)

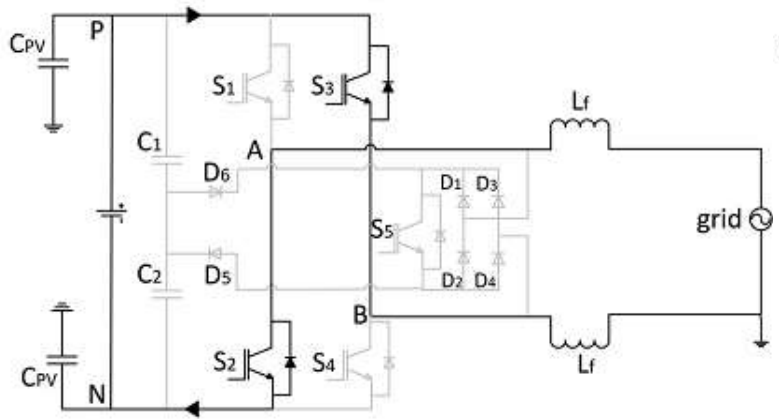

(c)

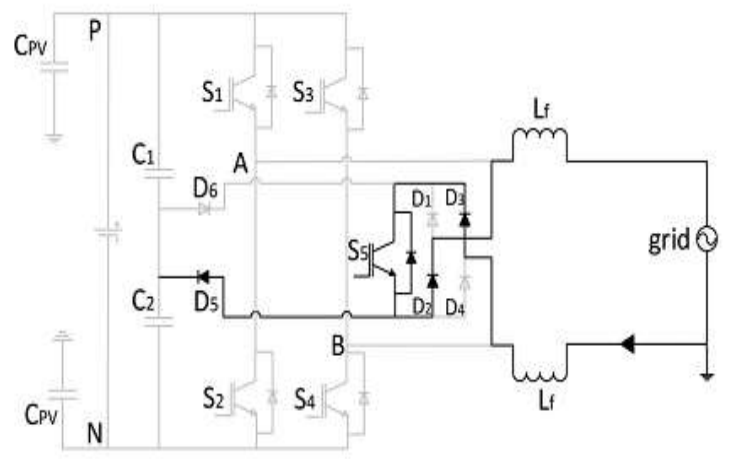

(b)

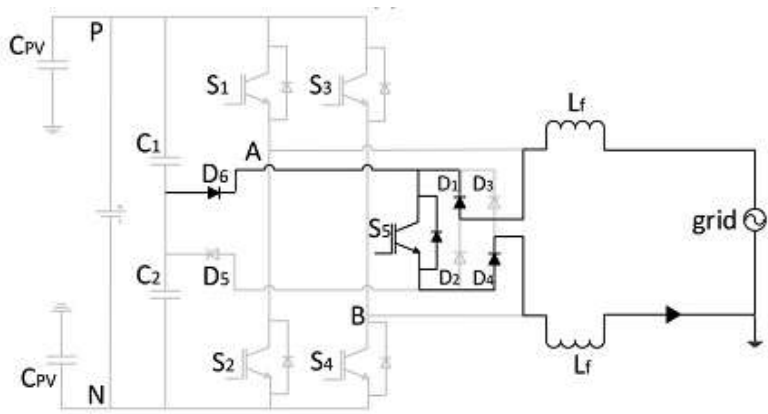

(d)

Figure 5. Operation modes of proposed HBZVR-D topology (a) Mode 1-conduction mode and (b) Mode 2freewheeling mode during positive half cycle

$$
\boldsymbol{V}_{C M}=\frac{\boldsymbol{V}_{A N}+\boldsymbol{V}_{B N}}{2}=\frac{1}{2}\left(\boldsymbol{V}_{D C}+0\right)=\frac{\boldsymbol{V}_{D C}}{2} .
$$

In mode 2, S1-S4are OFF.S5is ON to make a freewheeling Path. Current reductions and freewheels through diodesD3, and the network. The voltage VAN reductions and VBN increments until the point when their qualities achieve the regular point, $\mathrm{VDC} / 2$, with the end goal that $\mathrm{VAB}=0$. The $\mathrm{CMV}$ is.

$$
V_{C M}=\frac{V_{A N}+V_{B S}}{2}=\frac{1}{2}\left(\frac{V_{D C}}{2}+\frac{V_{D C}}{2}\right)=\frac{V_{D C}}{2}
$$

In mode 3, S2 and S3 are ON, while S1, S4 and S5 are OFF. Current increases and flows through S2 and $\mathrm{S} 3 . \mathrm{VAB}=-\mathrm{VDC}$. The CMV becomes

$$
\boldsymbol{V}_{C M}=\frac{\boldsymbol{V}_{A N}+\boldsymbol{V}_{B N}}{2}=\frac{1}{2}\left(0+\boldsymbol{V}_{D C}\right)=\frac{\boldsymbol{V}_{D C}}{2} .
$$

In mode 4, S1-S4 are OFF.S5is ON to make freewheeling way. Current reductions and freewheels through diodesD1, D4, and the framework. The voltage VAN abatements and VBN increments until the point that their qualities achieve the regular point, $\mathrm{VDC} / 2$, and $\mathrm{VAB}=0$. The CMV is as inferred in (10). Clearly, balance strategies are intended to produce Constant CMV in each of the four activity modes. All the exploration Works are outlined in view of the standards above. For all intents and purposes, VAN and VBN don't achieve regular point amid the freewheeling time frame (mode 2 and mode 4 ). It is appeared in reproduction and trial comes about later that the CMV isn't consistent without clasping branch. Amid the freewheeling time frame, both VAN and VBN are not braced to VDC/2 and is swaying with abundance 
relying upon the parasitic parameters and intersections' capacitance of those topologies. The enhanced clasping Branch of HBZVR-D guarantees the entire cinching of CMV to VDC/2 amid the freewheeling time frame. It is very much noticed that the Output current moves through just two switches in each conduction period (mode 1 and mode 3) as appeared in Figure 6 (a) and (c). This clarifies why HBZVR-D has moderately higher effectiveness than those of dc-decoupling topologies.

\subsection{Cactivity principles of improved clamping branch}

Amid the freewheeling time frame, S5 is turned ON, interfacing Point An and B. Freewheeling way voltage VFP can be characterized as $\mathrm{VFP}=\mathrm{VAN} \approx \mathrm{VBN}$, since the voltage drops crosswise over diodes and $\mathrm{S} 5$ are little contrasted with VDC. There are two conceivable methods of task (mode 2 and mode 4 as appeared in Figure 6) contingent upon whether D5 or D6 is forward one-sided. At the point when VFP is more prominent Than VDC/2, D5 is forward one-sided and D6 is turned around one-sided. Current streams from the freewheeling way to the midpoint of the dc-connect through the cinching diode D5, as appeared in Figure 6 (b), which totally clips the VFP to VDC/2. On alternate hands, when the VFP is not as much as VDC/2, D6 is forward one-sided and D5is switched one-sided. As appeared in Figure 6(d), current streams from the midpoint of the dc-connection to the freewheeling way through the additional clasping diodeD6, to expand the VFP to VDC/2. It ought to be noticed that amid the dead time between the conduction time frame and freewheeling period, the freewheeling way isn't all around braced and the CMV can be wavering with the lattice voltage. By the by, with legitimate determination of dead time, this impact can be limited. In HBZVR, the bracing branch comprises of D5 as it were. In this manner, the bracing of the freewheeling way is restricted just for the period when VFP is more than VDC/2. At the point when VFP is not as much as $\mathrm{VDC} / 2$, the cinching branch does not work on the grounds that D5 is turning around one-sided. Amid such condition, the CMV in HBZVR will sway, causing the stream of spillage current. This mishap is redressed by including a quick recuperation diodeD6 in the Proposed HBZVR-D topology. With both D5 and D6, the enhanced bracing branch ensures the total clipping of the CMV to VDC/2 all through the freewheeling time frame. Thus, spillage current, which is particularly subject to CMV, is totally disposed off.

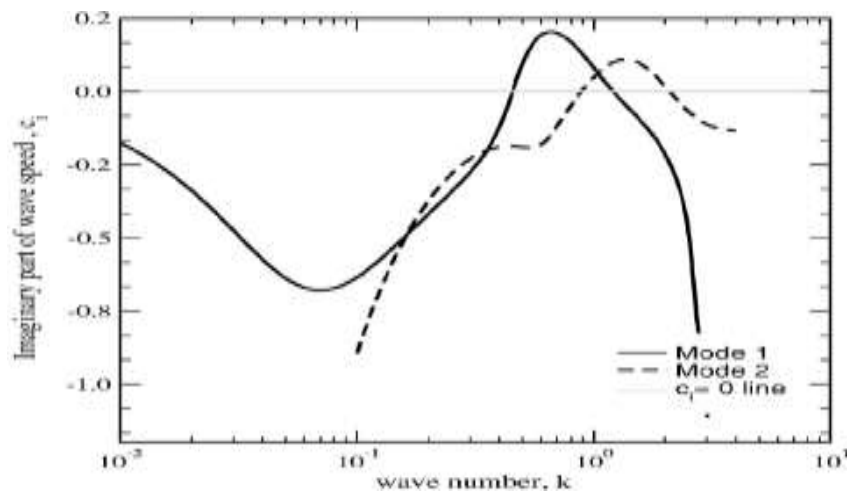

Figure 6. Mode 2 and Mode 4

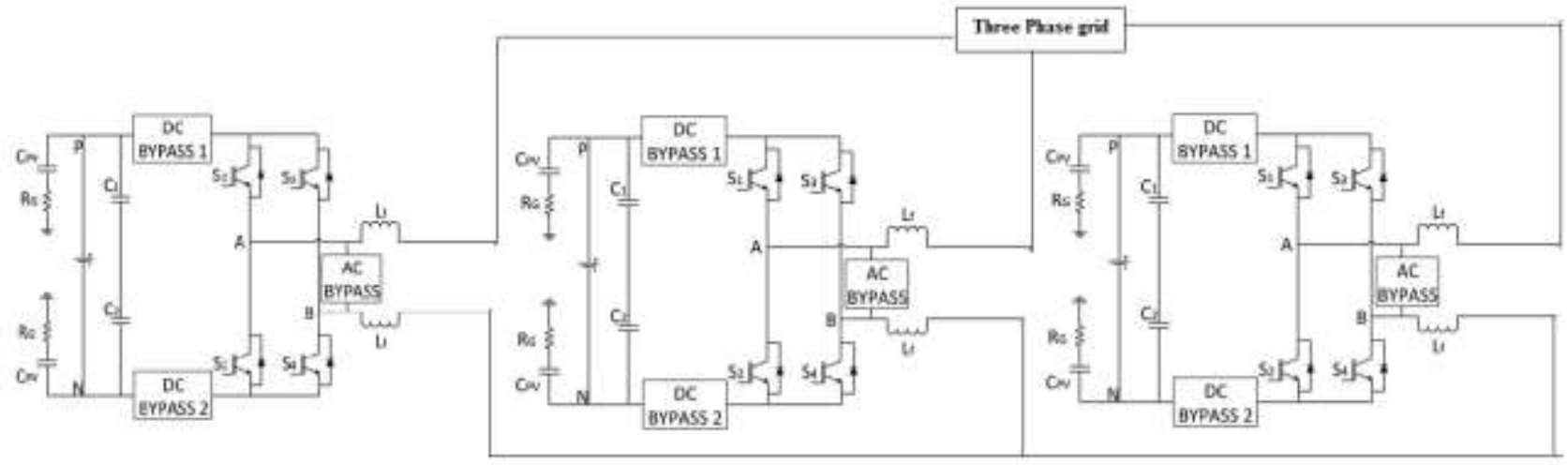

Figure 7.Three-phase transformer less PV inverters 


\section{MATLAB/SIMULATION RESULTS}

Figure 8 shows Matlab/Simulation model of H5 topology. Figure 9 shows simulation results of grid voltage and current, leakage current, VAN, VCM, VBN of H5 topology.

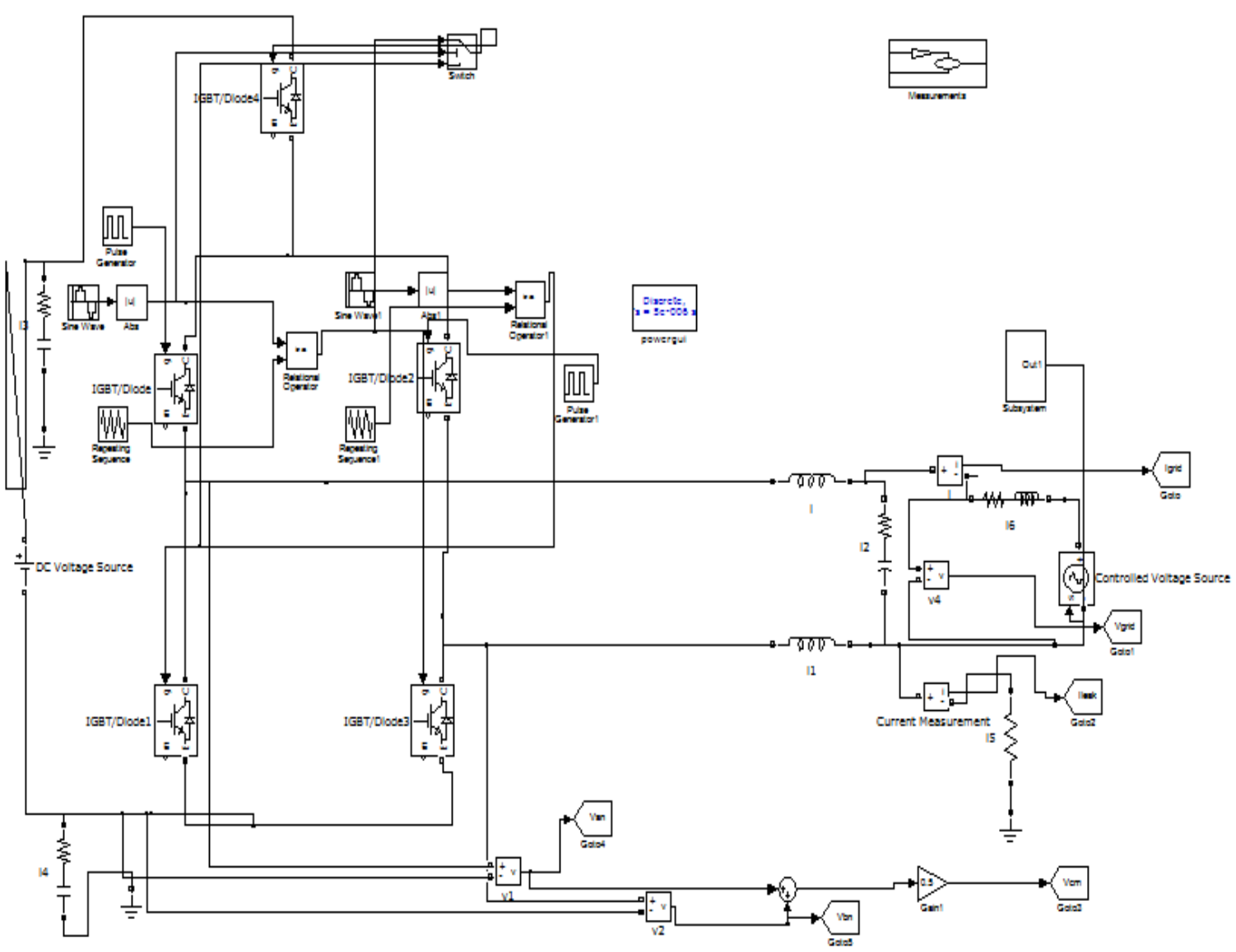

Figure 8. Matlab/simulation model of H5 topology

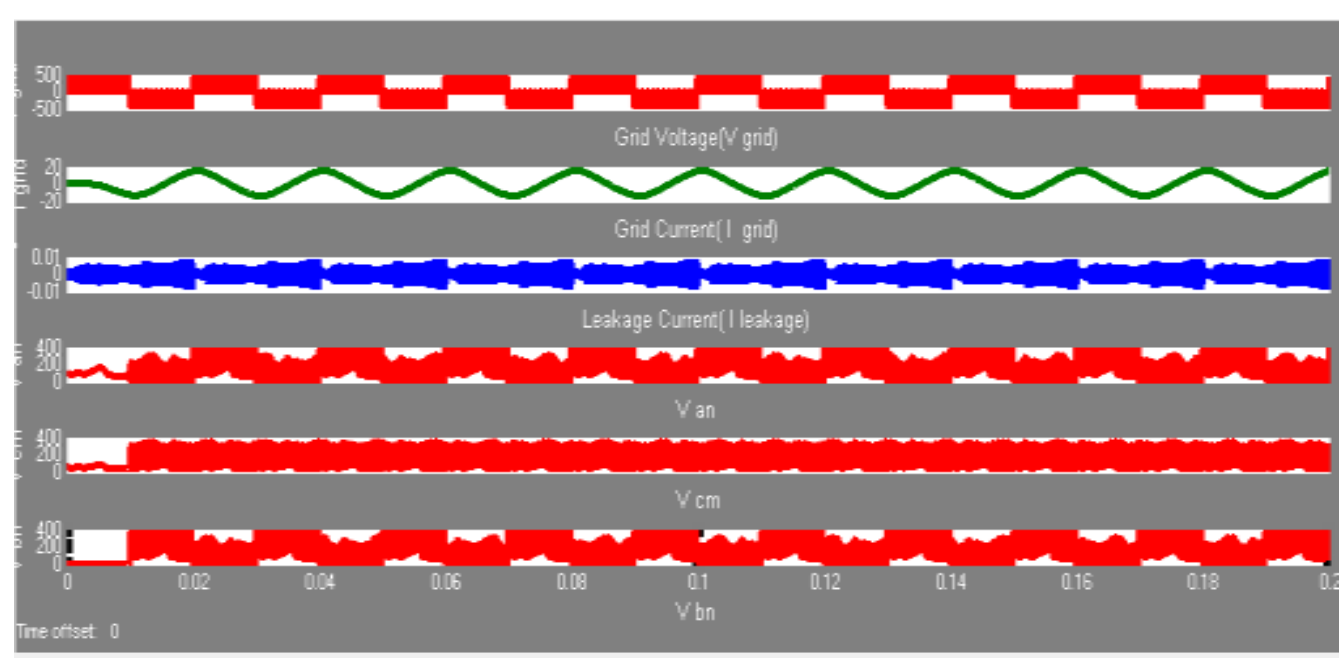

Figure 9. Simulation results of grid voltage and current, Leakage current, VAN, VCM, VBN of H5 topology 
Figure 10 shows Matlab/Simulation model of HERIC topology. Figure 11 shows simulation results of grid voltage and current, leakage current, VAN, VCM, VBN of HERIC converter.

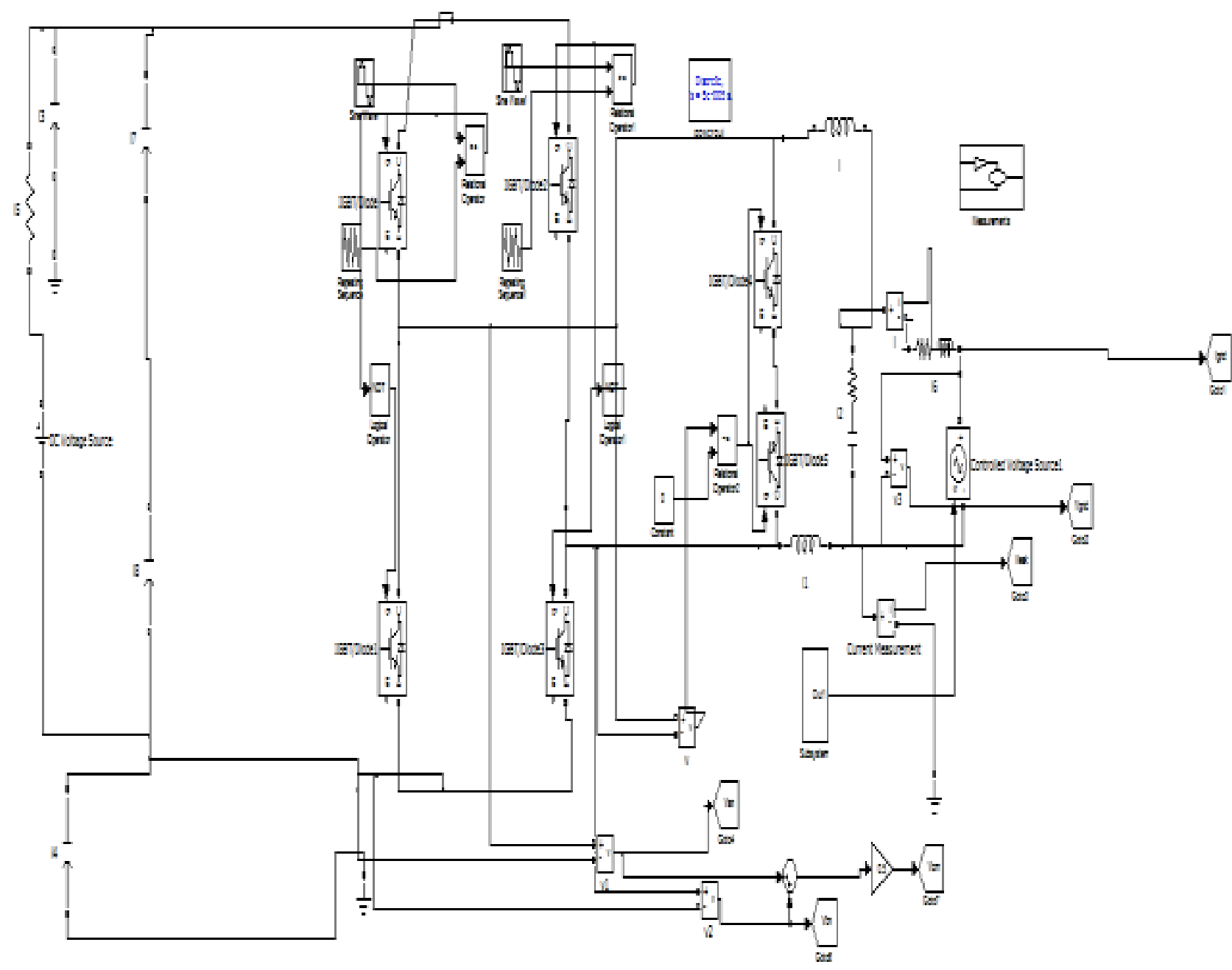

Figure 10. Matlab/simulation model of HERIC topology

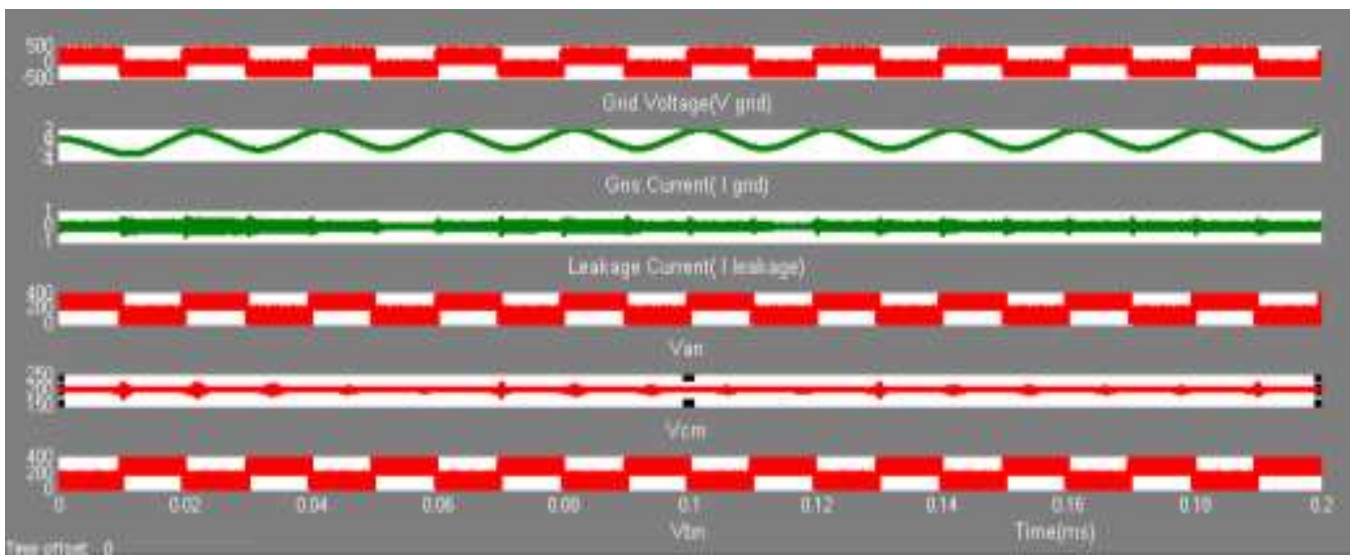

Figure 11. Simulation results of grid voltage and current, Leakage current, VAN, VCM, VBN of HERIC converter 
Figure 12 shows Matlab/simulation model of $\mathrm{OH} 5$ topology. Figure 13 shows simulation results for output voltage, grid current, leakage current, VAN, common mode voltage and VBN OH5 topology

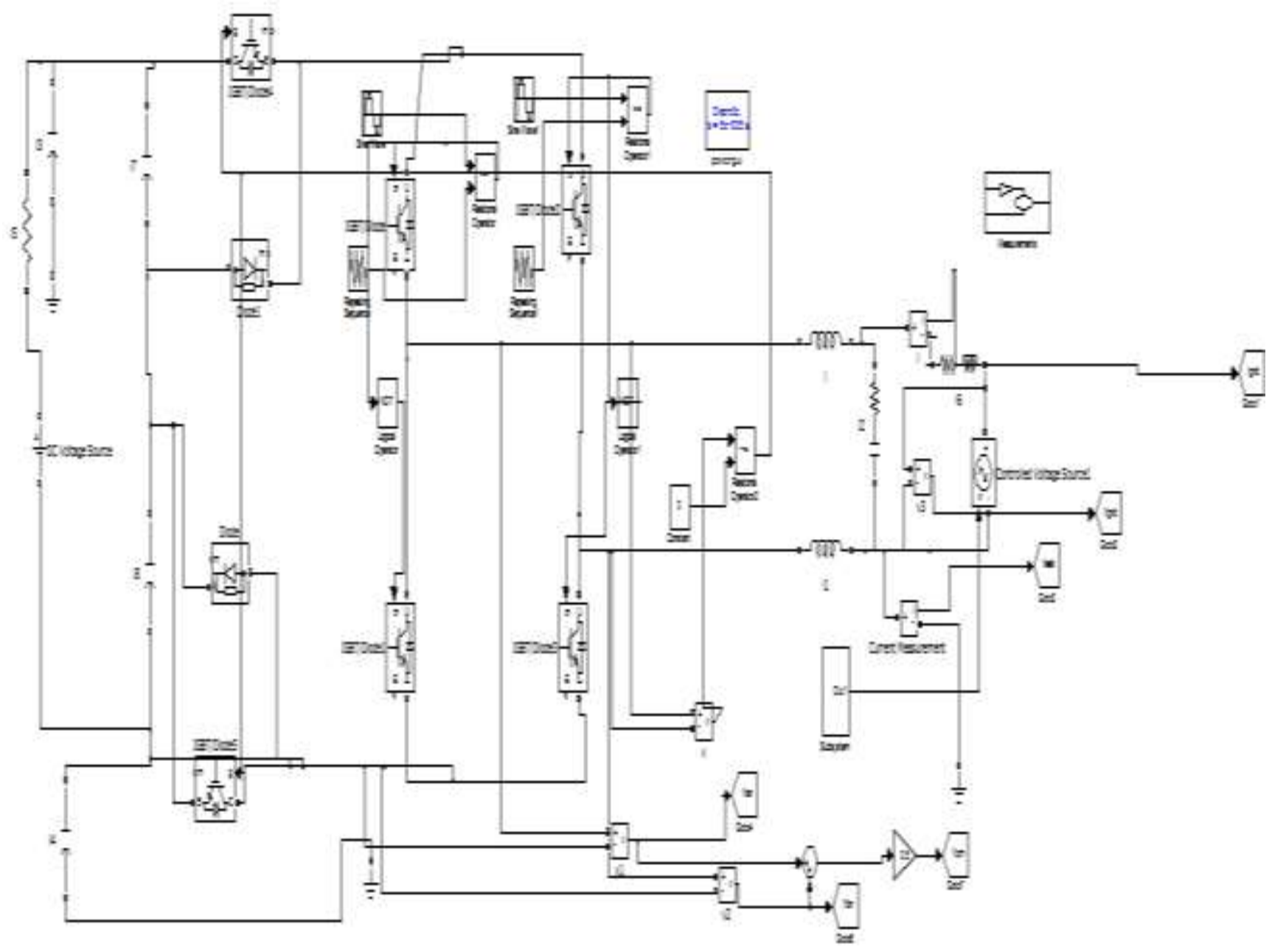

Figure 12. Matlab/simulation model of OH5 topology

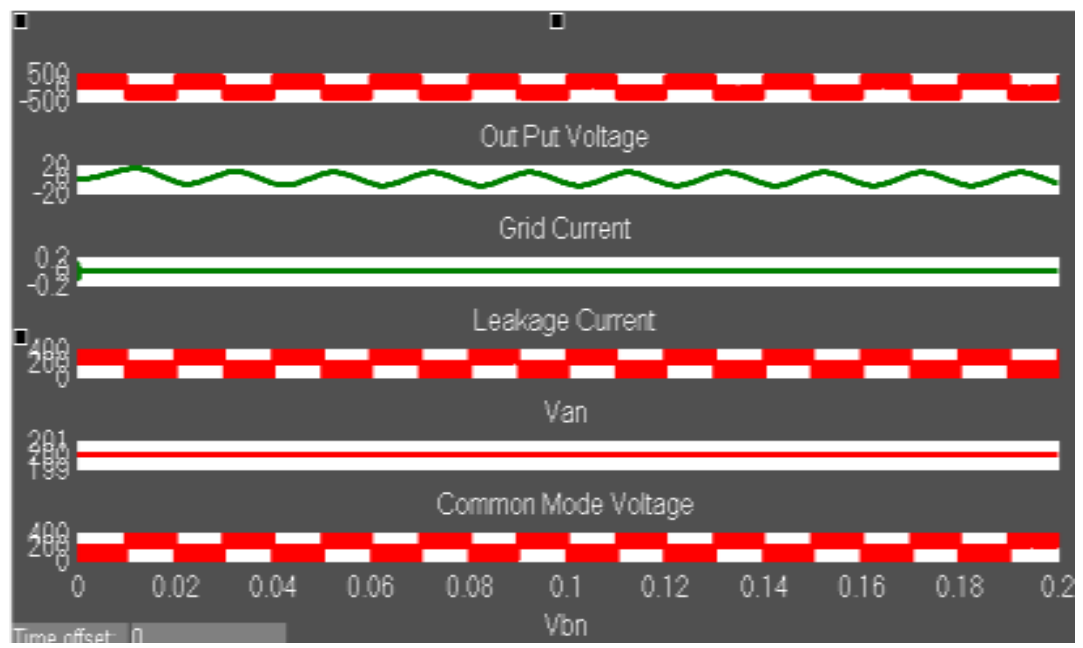

Figure 13. Simulation results for output voltage, grid current, leakage current, VAN, common mode voltage and VBN OH5 topology 
Figure 14 shows matlab/simulation model of H6 topology. Figure 15 shows simulation results of grid voltage and current, leakage current, VAN, VCM, VBN of H6 converter.

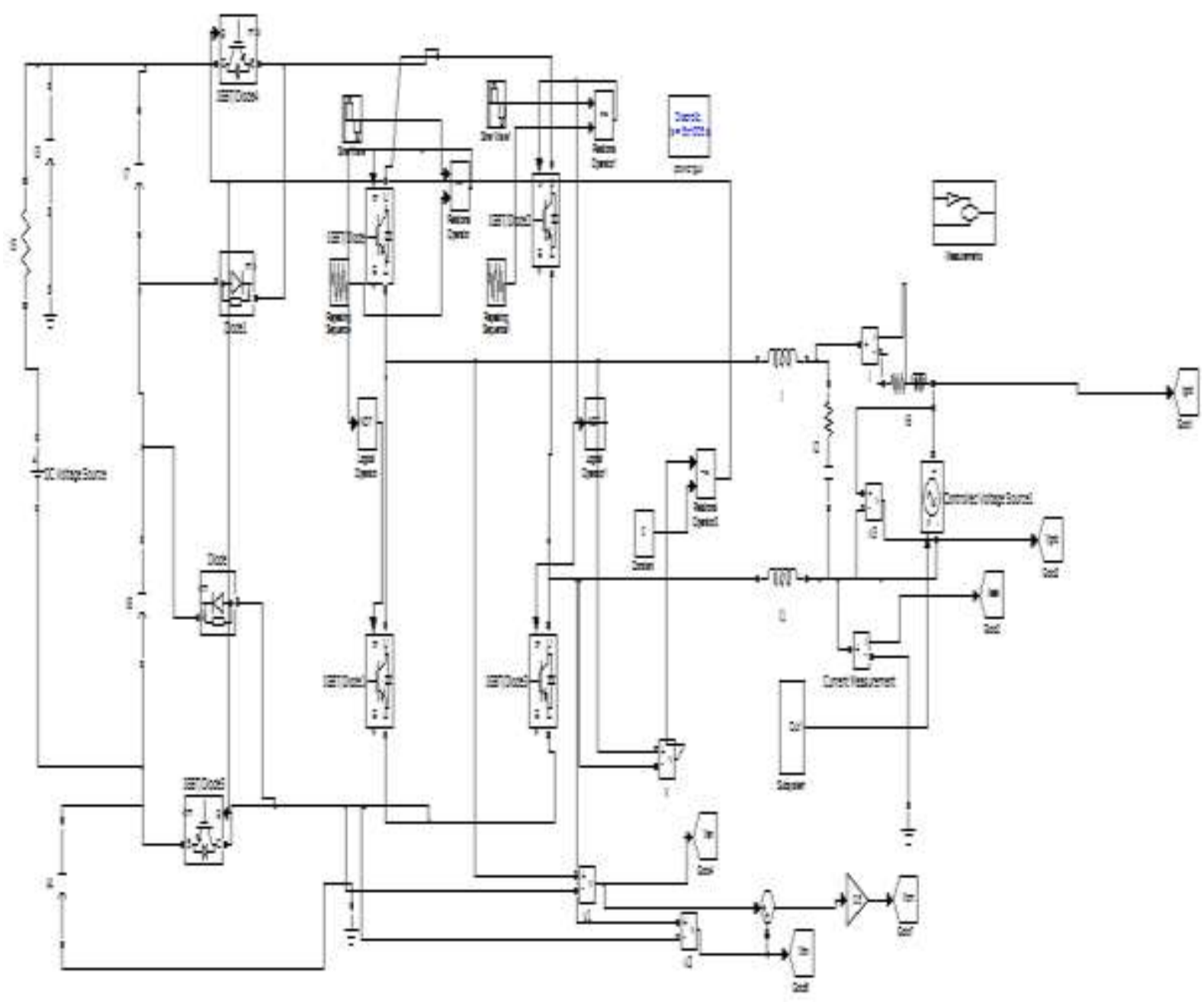

Figure 14. Matlab/simulation model of H6 topology

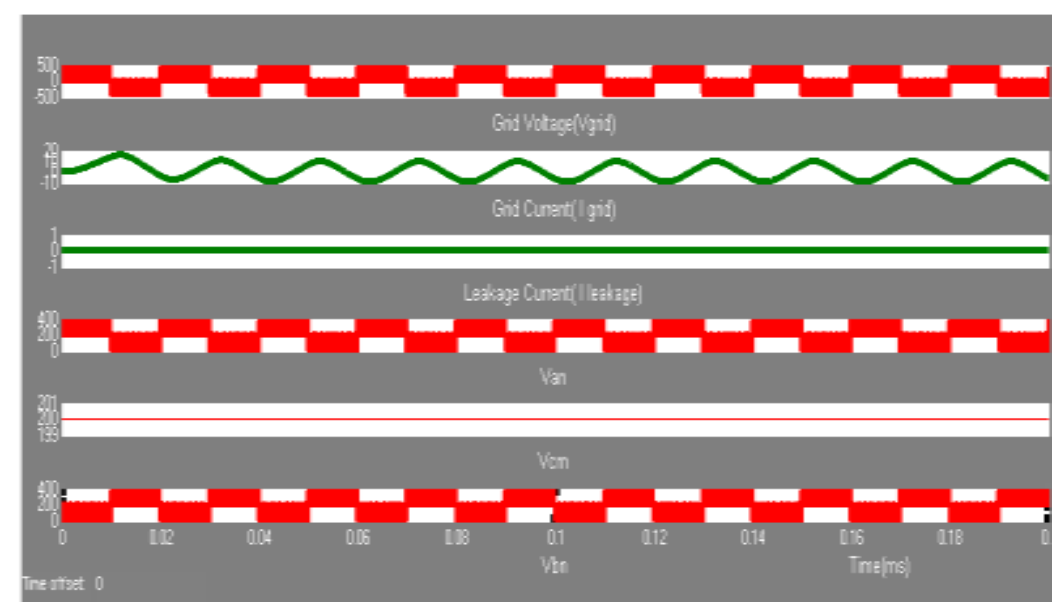

Figure 15. Simulation results of grid voltage and current, leakage current, VAN, VCM, VBN of H6 converter 
Figure 16 shows simulation model of HBZVR topology. Figure 17 shows simulation results of grid voltage and current, leakage current, VAN, VCM, VBN of HBZVR converter.

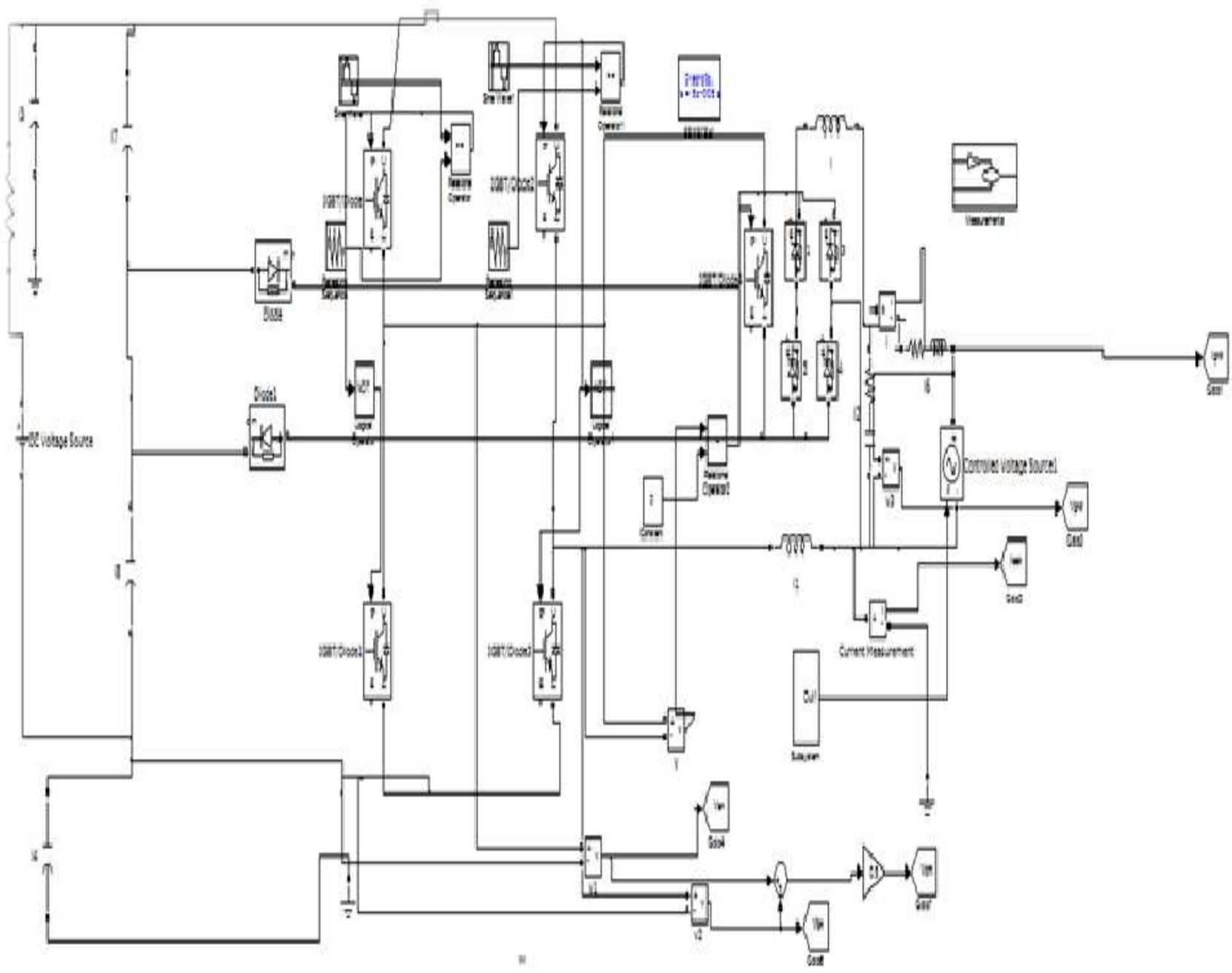

Figure 16. Simulation model of HBZVR topology

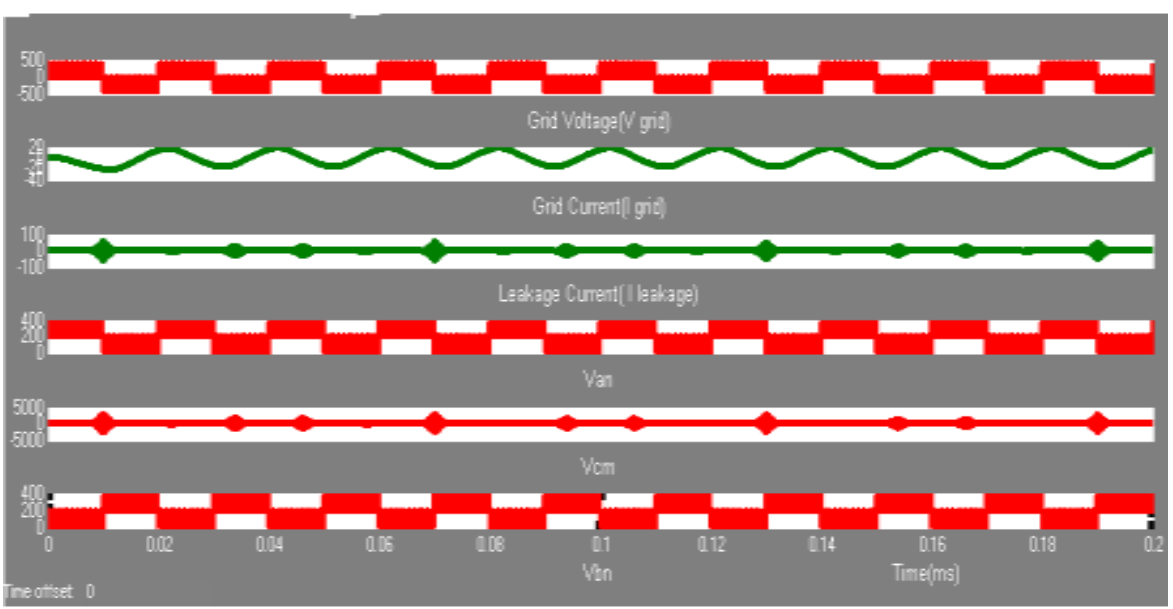

Figure 17. Simulation results of grid voltage and current, leakage current, VAN, VCM, VBN of HBZVR converter 
Figure 18 shows Matlab/Simulation model of HBZVR-D topology. Figure 19 shows simulation results of grid voltage and current, leakage current, VAN, VCM, VBN of HBZVR-D converter.

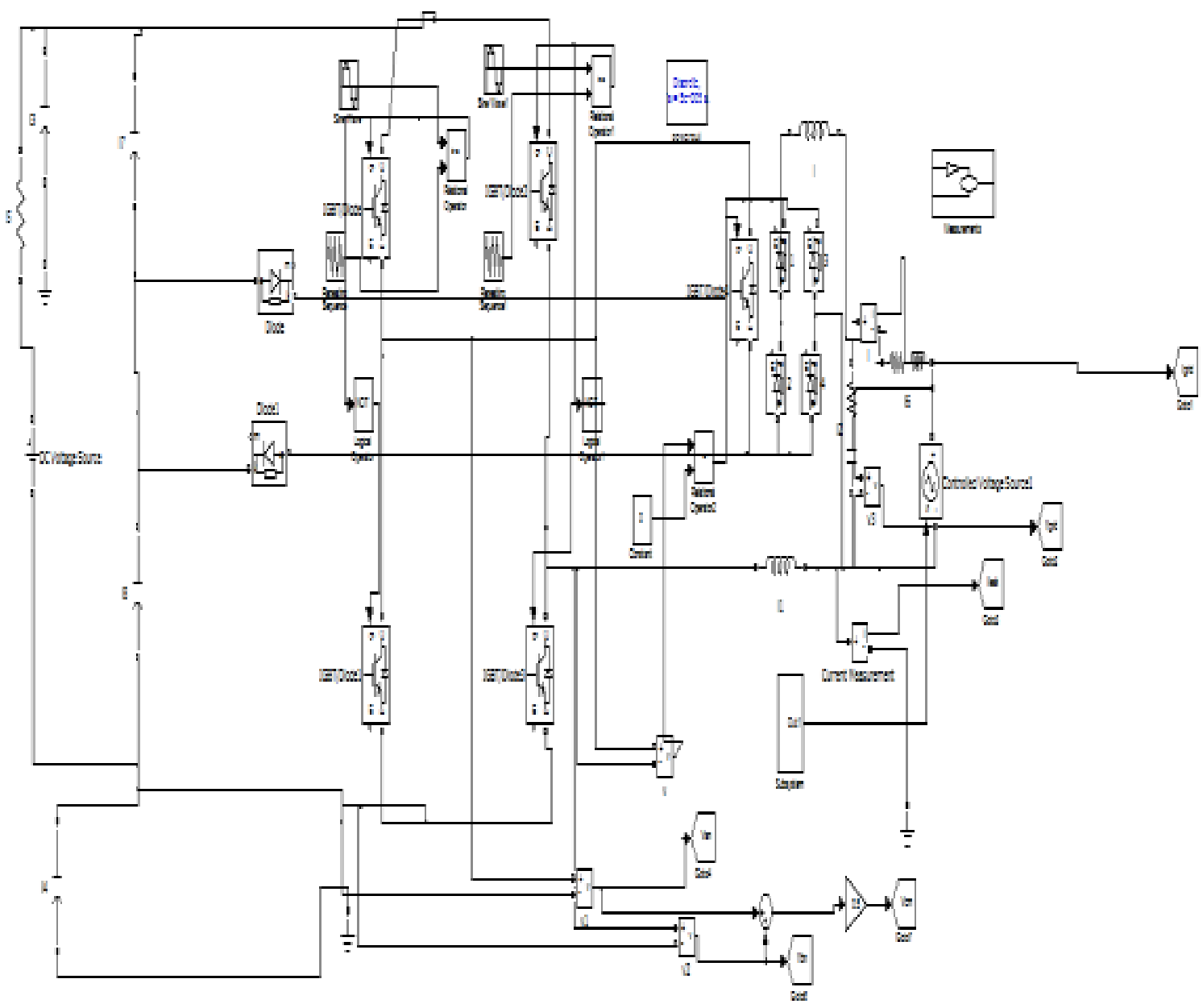

Figure 18. Matlab/Simulation model of HBZVR-D topology

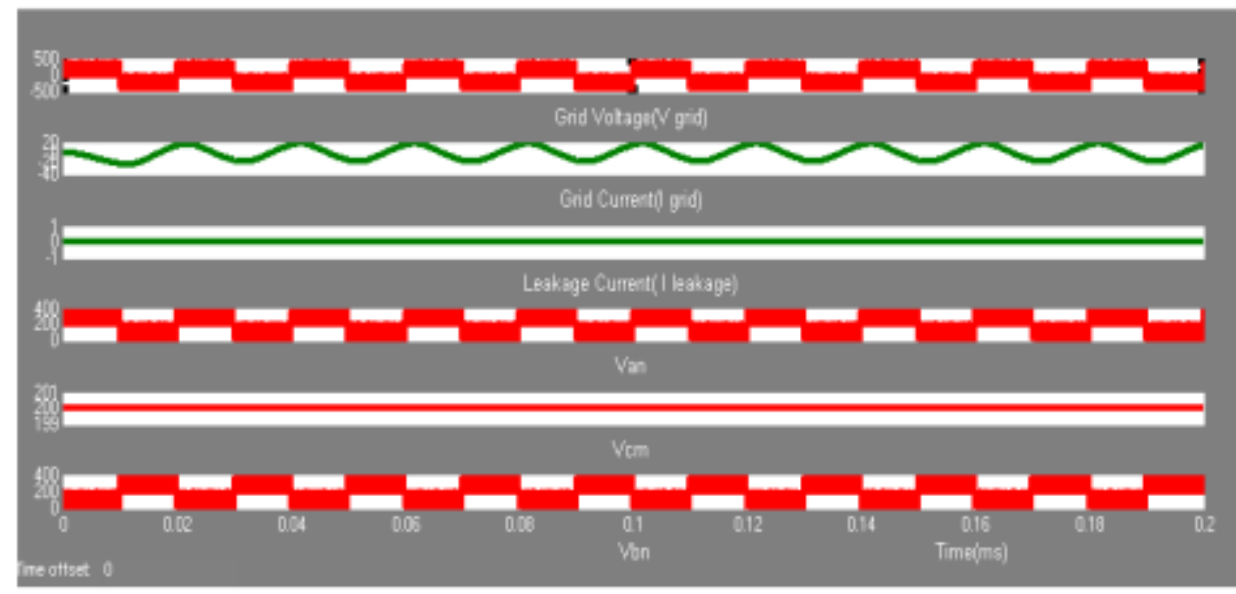

Figure 19. Simulation results of grid voltage and current, leakage current, VAN, VCM, VBN of HBZVR-D converter 
Figure 20 shows simulation model of three-level three-phase PV inverter topology. Figure 21 shows grid voltage and grid current in three level three-phase full-bridge transformer less PV inverter. Figure 22 shows CMV and leakage current in three-level three phase transformer less PV inverters.
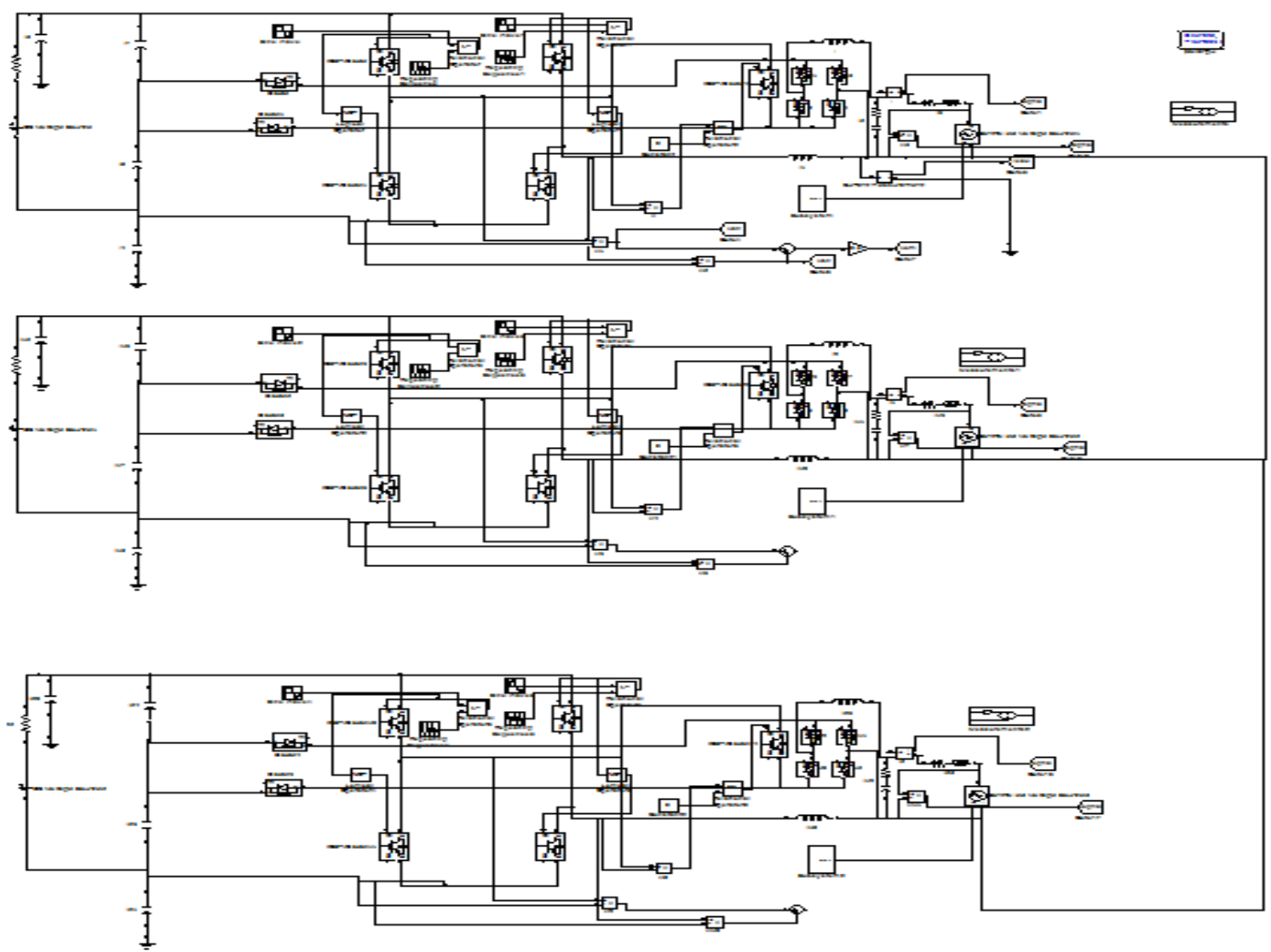

Figure 20. Simulation model of three-level three-phase PV inverter topology

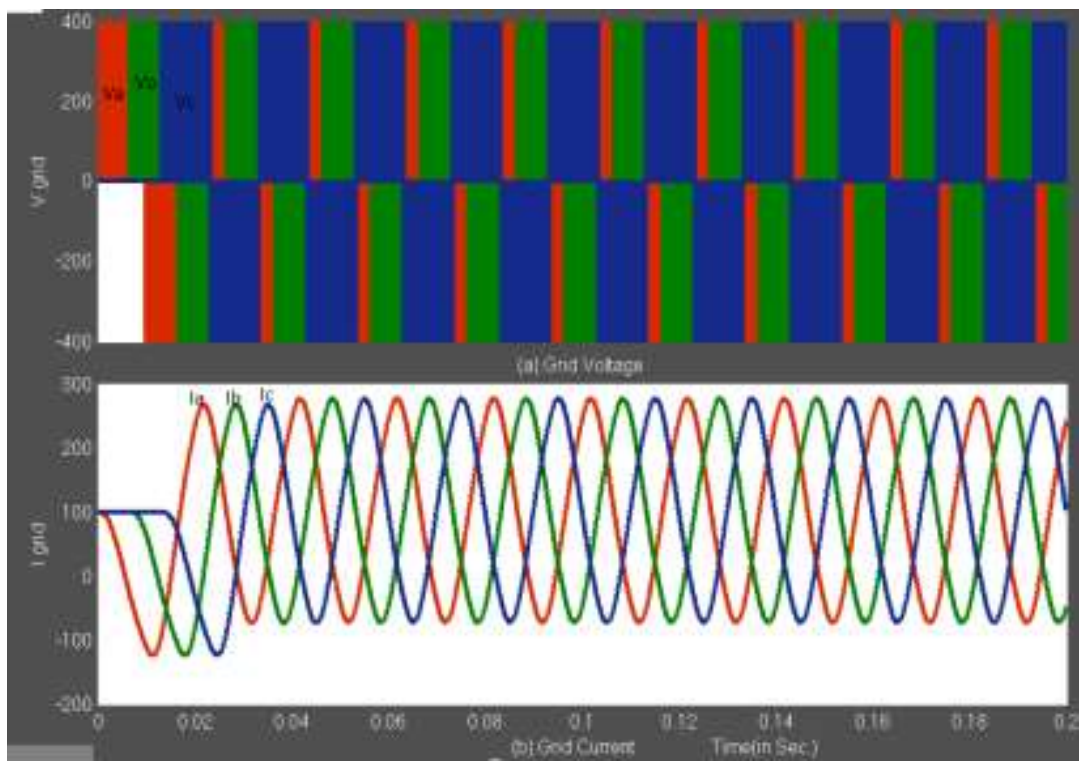

Figure 21. Grid voltage and grid current in three level three-phase full-bridge transformer less PV inverter 


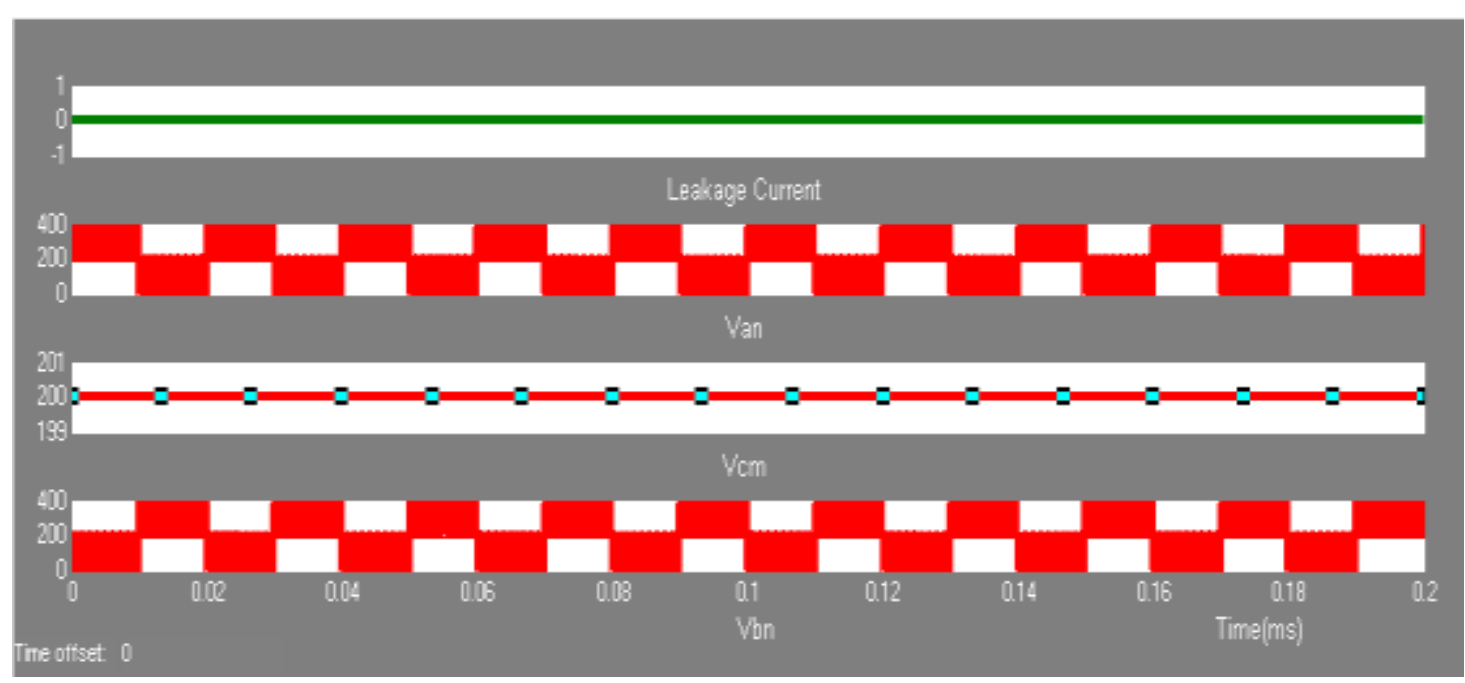

Figure 22. CMV and leakage current in three-level three phase transformer less PV inverters

\section{CONCLUSION}

The execution of paper actualized in the three stage network associated. A high dependability and proficiency inverter for transformer less PV matrix associated control age frameworks is displayed in this paper. Ultra high proficiency can be accomplished over a wide yield control run by dependably utilizing super intersection MOSFETs for all switches since their body diodes are never enacted and no shoot-through issue prompts incredibly improved unwavering quality. Low air conditioning yield current mutilation is accomplished in light of the fact that dead time isn't required at PWM exchanging substitution moments and lattice cycle zero-intersection moments. The higher working frequencies with high proficiency empowers diminished cooling necessities and results in framework cost reserve funds by contracting aloof parts. The proposed converter three stage lattice associated. The protected works, for example, H5 and HERIC, give galvanic disengagement to security purposes. All things considered, their CMVs are not clasped and spillage streams are not totally killed .Other topologies, for example, OH5 and H6, dispose of the spillage current with the utilization of both galvanic confinement and CMV clipping, to the detriment of lessened framework effectiveness. By utilizing air conditioning decoupling technique rather than dc-decoupling strategy for galvanic disengagement, HBZVR and HERIC figure out how to accomplish higher proficiency than the rest yet perform inadequately as far as regular mode conduct. With the comprehension on the benefits and bad marks of the diverse methodologies, a changed HBZVR topology is gotten by expansion of a quick recuperation diode. The proposed topology (known as HBZVR-D) joins the upsides of the low misfortune air conditioning decoupling strategy and the entire spillage current disposal of the CMV cinching technique. The execution of the transformer less topologies, including the proposed HBZVR-D, is analyzed as far as CMV, spillage current, misfortunes, THD, and productivity. It is tentatively demonstrated that HBZVR-D topology gives the best general execution and is reasonable for transformer less PV applications for a 230-V (rms) matrix framework.

\section{REFERENCES}

[1] F. Tan Kheng Suan, N. A. Rahim and W. P. Hew, "Modeling, analysis and control of various types of transformerless grid connected PV inverters," 2011 IEEE Conference on Clean Energy and Technology (CET), Kuala Lumpur, 2011, pp. 51-56.

[2] N. A. Rahim, K. Chaniago and J. Selvaraj, "Single-Phase Seven-Level Grid-Connected Inverter for Photovoltaic System," in IEEE Transactions on Industrial Electronics, vol. 58, no. 6, pp. 2435-2443, June 2011.

[3] G. Petrone, G. Spagnuolo, R. Teodorescu, M. Veerachary and M. Vitelli, "Reliability Issues in Photovoltaic Power Processing Systems," in IEEE Transactions on Industrial Electronics, vol. 55, no. 7, pp. 2569-2580, July 2008.

[4] M. Calais, J. Myrzik, T. Spooner and V. G. Agelidis, "Inverters for single-phase grid connected photovoltaic systems-an overview," 2002 IEEE 33rd Annual IEEE Power Electronics Specialists Conference. Proceedings (Cat. No.02CH37289), Cairns, Qld., Australia, 2002, pp. 1995-2000 vol.4.

[5] J. Shen, H. Jou and J. Wu, "Novel Transformerless Grid-Connected Power Converter With Negative Grounding for Photovoltaic Generation System," in IEEE Transactions on Power Electronics, vol. 27, no. 4, pp. 1818-1829, April 2012. 
[6] S. V. Araujo, P. Zacharias and R. Mallwitz, "Highly Efficient Single-Phase Transformerless Inverters for GridConnected Photovoltaic Systems," in IEEE Transactions on Industrial Electronics, vol. 57, no. 9, pp. 3118-3128, Sept. 2010.

[7] Ó. López et al., "Eliminating Ground Current in a Transformerless Photovoltaic Application," in IEEE Transactions on Energy Conversion, vol. 25, no. 1, pp. 140-147, March 2010.

[8] T. Kerekes, R. Teodorescu, M. Liserre, C. Klumpner and M. Sumner, "Evaluation of Three-Phase Transformerless Photovoltaic Inverter Topologies," in IEEE Transactions on Power Electronics, vol. 24, no. 9, pp. 2202-2211, Sept. 2009.

[9] B. N. Alajmi, K. H. Ahmed, G. P. Adam and B. W. Williams, "Single-Phase Single-Stage Transformer less GridConnected PV System," in IEEE Transactions on Power Electronics, vol. 28, no. 6, pp. 2664-2676, June 2013.

[10] Y. Gu, W. Li, Y. Zhao, B. Yang, C. Li and X. He, "Transformerless Inverter With Virtual DC Bus Concept for Cost-Effective Grid-Connected PV Power Systems," in IEEE Transactions on Power Electronics, vol. 28, no. 2, pp. 793-805, Feb. 2013.

[11] D. Meneses, F. Blaabjerg, Ó. García and J. A. Cobos, "Review and Comparison of Step-Up Transformerless Topologies for Photovoltaic AC-Module Application," in IEEE Transactions on Power Electronics, vol. 28, no. 6, pp. 2649-2663, June 2013.

[12] L. Zhang, K. Sun, L. Feng, H. Wu and Y. Xing, "A Family of Neutral Point Clamped Full-Bridge Topologies for Transformerless Photovoltaic Grid-Tied Inverters," in IEEE Transactions on Power Electronics, vol. 28, no. 2, pp. 730-739, Feb. 2013.

[13] E. Koutroulis and F. Blaabjerg, "Design Optimization of Transformerless Grid-Connected PV Inverters Including Reliability," in IEEE Transactions on Power Electronics, vol. 28, no. 1, pp. 325-335, Jan. 2013.

[14] Automatic Disconnection Device between a Generator and the Public Low-Voltage Grid, DIN Electro technical Standard DIN. 